\title{
A FILOSOFIA DA EDUCAÇÃO ENTRE A TEORIA CRÍTICA
}

\author{
E A FILOSOFIA DA DIFERENÇA
}

Profa. Dra. Cristiane Marinho ${ }^{1}$

\section{RESUMO}

O presente artigo aborda a polêmica entre o Marxismo e a Filosofia da Diferença no âmbito da Filosofia da Educação, área de conhecimento que se modifica conforme mudam as ideias sobre Educação e Filosofia. O item Teoria Crítica e Filosofia da Educação tem o pensamento adorniano como eixo central, bem como o conceito de Formação (Bildung), Semiformação (Halbbildung) na perspectiva da emancipação humana. Já o item Filosofia da Diferença e Filosofia da Educação se baseia no pensamento deleuzeano e desconstrói a ideia de emancipação a partir das mudanças conceituais de Educação e Filosofia, e também apresenta seus substitutos nas noções de criatividade e de universo micro. Outro objetivo do presente texto é explicitar os pontos positivos trazidos pela Filosofia da Educação norteada pela Filosofia da Diferença, encontro nem sempre bem visto por alguns estudiosos da Teoria Crítica.

Palavras-chaves: Filosofia da Educação; Teoria Crítica; Filosofia da Diferença; Adorno; Deleuze

\begin{abstract}
This paper discusses the controversy between Marxism and the Philosophy of Difference within the framework of the Philosophy of Education, area of knowledge that modifies itself as the ideas about Education and Philosophy also change. The item Critical Theory and Philosophy of Education has the Adornian's thought as the central axis, as well as the concept on Formation (Bildung), Semiformation (Halbbildung) from the perspective of human emancipation. Yet the item Philosophy of Difference and Philosophy of Education is based on the Deleuzian`s thought and desconstructs the idea of emancipation from the conceptual changes in Education and Philosophy, and also presents their substitutes on the notions of creativity and micro universe. Another objective of this paper is to explain the positive aspects brought by the Philosophy of Education, guided by the Philosophy of Difference, which is not always well regarded by some scholars of the Critical Philosophy.
\end{abstract}

Keywords: Philosophy of Education; Critical Theory;Philosophy of Difference;Adorno; Deleuze.

\footnotetext{
${ }^{1}$ Graduada em Filosofia (FAFIFOR); Mestra em Filosofia (UFPB); Doutora em Educação (UFC); Pósdoutora em Filosofia da Educação (UNICAMP); Professora de Filosofia da UECE - Curso de Filosofia e Mestrado Acadêmico de Serviço Social (MASS); Coordenadora do Grupo de Estudos Foucaultianos (GEF) e do Laboratório de Estudos Foucaultianos (LAPEF) da UECE.
} 


\section{1- Introdução}

Muito se tem falado sobre a polêmica entre o Marxismo e a Filosofia da Diferença também no âmbito da Filosofia da Educação. O presente artigo busca contribuir com este debate apresentando a Filosofia da Educação como uma área de conhecimento que vai se modificando conforme mudam as ideias sobre Educação e Filosofia. Assim, o item Teoria Crítica e Filosofia da Educação demonstra que aquela relação tem por eixo central, no pensamento adorniano, o conceito de Formação (Bildung), Semiformação (Halbbildung) na perspectiva da emancipação humana.

Já o item Filosofia da Diferença e Filosofia da Educação demonstra que, em função da mudança do que se entende sobre Educação e Filosofia, a proposta pósmoderna desconstrói a ideia de emancipação como algo que possa ser ensinado ou repassado e afirma a noção de criatividade e de universo micro, abordado aqui no pensamento deleuziano.

Portanto, buscamos demonstrar que a Filosofia da Educação vai se modificando em conformidade com a própria mudança do que se entende sobre o que é Filosofia e o que é Educação. Da mesma forma, objetivamos explicitar os pontos positivos trazidos pela Filosofia da Educação norteada pela Filosofia da Diferença, encontro tão atacado por alguns estudiosos da Teoria Crítica.

\section{2- Filosofia da Educação}

A educação sempre foi objeto de reflexão da Filosofia. Umas vezes de forma central, outras vezes de forma tangencial. Desde o início a filosofia se preocupa com a educação enquanto formação do homem, ideia que vai se modificando historicamente e se reveste de várias denominações que expressam as respectivas épocas e as reflexões filosóficas aí constituídas: a paidéia grega, a humanitas renascentista, a Bildung iluminista e um novo conceito contemporâneo ainda indefinido, mas questionador da ideia central de formação humana presente nos outros conceitos.

Apesar de, ao longo da História da Filosofia, diversos filósofos terem refletido conceitualmente em diversas obras sobre formação humana, por muito tempo a Filosofia da Educação não foi tida como uma reflexão sistemática e autônoma. Na França, até o final do século XIX e durante o século XX, até a década de 1970, a

\begin{tabular}{|l|l|l|l|l|}
\hline Q Ronista Dialectus & Ano 2 & n.5 & Agosto - Dezembro 2014 & p. 125 - 139 \\
\hline
\end{tabular}


expressão Pedagogia Geral era utilizada como sinônimo de Filosofia da Educação. (Tomazetti, 2003, p. 21).

A Filosofia da Educação era uma pedagogia teórica chamada de pedagogia Filosófica, continuidade da tradição filosófico-pedagógica do final do século XVIII e início do século XIX, a partir das reflexões de filósofos como Kant, Fichte, Scheling, Schleiermacher, Herbart, Nietzsche, Schopenhauer e Dilthey. Assim, a pedagogia, enquanto filosofia da educação, tomava da filosofia geral os fundamentos últimos da vida, do homem, do conhecimento e do saber e procurava realizá-los na prática educativa (Ibid., p. 23). Dessa forma,

Foi a importância que teve os fundamentos da Filosofia para a constituição da Pedagogia que aproximou estes dois universos teóricos e deixou para a Filosofia da Educação o legado de um conjunto de saberes relacionados à prática educativa. Somente quando a Pedagogia deixa de se sustentar nos fundamentos filosóficos, em uma busca de totalidade científica, é que a Filosofia da Educação se torna autônoma como pensamento mais sistematizado (MARINHO, 2012).

Ou seja, foi o abandono do discurso filosófico como fundamento principal do saber pedagógico que possibilitou a constituição das ciências da educação e fez com que a Filosofia da Educação se sistematizasse com um discurso próprio, porém inferior. Essa hierarquia predomina no século XX com o Positivismo inaugurando a distinção entre "um discurso científico sobre a educação, representado pela Pedagogia (científica), e um discurso generalista/totalizante sobre a educação: o discurso filosófico sobre a educação" (Tomazetti, 2003, pp. 25, 28). A partir daí, a reflexão filosófica começava a ser classificada como menos importante que uma reflexão científica sobre a educação.

Resultou daí a separação entre o discurso pedagógico e o discurso filosófico, bem como o rebaixamento deste último a discurso pré-científico, lugar inferior para quem já tinha sido fundamento do primeiro. Durkheim foi, em grande parte, o responsável pela cientificização sociológica do discurso da educação e do rebaixamento do conhecimento filosófico ao retirar da Filosofia a condição de saber-fundamento da educação, pois era especulativa e sem objetividade. Diversamente, a Sociologia é que era a ciência legítima para a análise da educação, com a Psicologia e a História como ciências auxiliares. Nesse âmbito,

[...] a Filosofia foi excluída do discurso educacional ou considerada saber de menor importância. As temáticas da educação, a partir de

\begin{tabular}{|l|l|l|l|l|}
\hline Govista Dialectus & Ano 2 & n.5 & Agosto - Dezembro 2014 & p. 125 - 139 \\
\hline
\end{tabular}


então, seriam objetos das diferentes ciências da educação e a Filosofia, com a perda de sua hegemonia, passaria a disputar espaço para proferir o seu discurso sobre a educação (Ibid., p. 30).

Segundo Tomazetti, a revalorização da Filosofia da Educação, juntamente com a Psicologia, a Sociologia e a História da Educação, ocorreu na década de 1960, na Inglaterra, onde professores, premidos pela sobrecarga do ensino de todo o conteúdo dessas disciplinas desde o início do século XX, se articularam na defesa de um ensino mais específico de cada uma dessas matérias. Dessa luta resultou um enorme desenvolvimento da Filosofia e da Sociologia da Educação no campo da Filosofia Analítica, o qual foi criticado posteriormente por ter se distanciado da prática educativa e docente. Dessa nova realidade, resultou um movimento que reivindicava uma volta às questões mais ligadas à prática educativa.

Por um lado, a Pedagogia científica criticava na Pedagogia tradicional a falta de fundamentação científica, a ausência de atividades práticas, a erudição supérflua e o enciclopedismo inútil. Por outro lado, a Filosofia da Educação tornou-se um saber independente com a consolidação das ciências da educação, deixando de se identificar com a Pedagogia teórica ou Pedagogia filosófica, mas trazendo como herança algumas de suas principais características, tais como a preocupação com a história das ideias da educação dos grandes filósofos e suas concepções de homem, de conhecimento e de valor. Assim,

caberia, então, à Filosofia da Educação a reflexão sobre os fins e os valores da educação, a partir de uma determinada teoria filosóficopedagógica. Permaneceria sua caracterização como um saber teórico e especulativo, de menor importância em relação ao saber científico da educação (Ibid., p. 41).

No contexto do avanço das ciências da educação, o interesse da Filosofia da Educação era as ideias sobre educação dos filósofos como, por exemplo, Platão, Locke, Rousseau, Kant, e o conhecimento dos principais sistemas filosóficos, dos quais se deduziam os conceitos de educação, de homem, de escola etc. Já o objetivo principal da disciplina Filosofia da Educação, nesse contexto, passou a ser "a definição dos fins que deveriam ser alcançados pelo processo educativo e os valores que deveriam ser transmitidos aos alunos" (Ibid., p. 191). Dessa forma, conforme Tomazetti, a disciplina

\begin{tabular}{|l|l|l|l|l|}
\hline Q Rovista Dialectus & Ano 2 & n.5 & Agosto - Dezembro 2014 & p. 125 - 139 \\
\hline
\end{tabular}


se transformou em uma reflexão abrangente sobre educação, indo muito além da instrução das teorias psicológicas e da moralização social proposta pela Sociologia.

Quanto ao ensino da Filosofia da Educação na tradição, é possível afirmar que transcorreu, prioritariamente, a partir do estudo das ideias sobre educação de importantes filósofos no contexto da história da Filosofia. O professor, partindo de seus conhecimentos em História e em Filosofia, aproximava as duas áreas e definia os conteúdos a serem ensinados a partir de uma dimensão histórica da Filosofia que, por sua vez, era complementada pelo estudo de pensadores clássicos e das principais correntes filosóficas. Assim, a Filosofia da Educação era a apresentação do pensamento dos filósofos e suas ideias acerca da educação e ensinar Filosofia da Educação era descrever a história desse pensamento educacional/filosófico, extraindo daí as temáticas características do saber filosófico da educação (a ética, a estética, o homem, o conhecimento, os valores e os fins) e sua relação com a educação. Assim, assevera Tomazetti:

[...] conceitos clássicos de educação, educação e ciência, natureza do ato pedagógico, fins e valores da educação, possibilidades da educação e correntes da Filosofia da Educação, entre outros, marcaram, em grande medida, a tradição dos estudos de Filosofia da Educação (Ibid., p. 249).

Ainda conforme Tomazetti, o perfil que foi se delineando na constituição da cadeira de História e Filosofia da Educação mostrou que saber filosófico e saber histórico eram indissociáveis na compreensão das questões educacionais e da concepção de educação como formação geral do homem e da cultura, mas não dos métodos e técnicas para a eficiência do ensino. A Filosofia da Educação, por sua vez, era um estudo sobre as ideias dos grandes filósofos da educação, situadas na História da Educação e na Pedagogia, demonstrando que os limites entre um saber e outro eram muito tênues. Atualmente há um redimensionamento desses estudos, ficando mais demarcados os limites entre História da Educação e Filosofia da Educação, apesar de continuarem tidos como complementares.

Essa complementariedade de saberes filosófico e histórico da educação é justificada pela compreensão de que a ideia de Formação (Bildung) era a espinha dorsal da educação, sendo também da competência da disciplina Filosofia da Educação auxiliar nessa Formação nos moldes da Paideia grega ou da Bildung alemã expondo a

\begin{tabular}{|l|l|l|l|l|}
\hline Q Ronista Dialectus & Ano 2 & n.5 & Agosto - Dezembro 2014 & p. 125 - 139 \\
\hline
\end{tabular}


história da cultura, história dos grandes ideais da formação humana e as grandes ideias dos filósofos da educação, bem como suas principais obras.

\section{3- Teoria Crítica e Filosofia da Educação}

A Teoria Crítica se refere ao pensamento de um grupo de intelectuais alemães marxistas não ortodoxos que, a partir de 1920, desenvolveram pesquisas de cunho filosófico, econômico, social, cultural e estético, mas sempre estabelecendo um diálogo com a tradição filosófica, demarcando sua posição anti economicista e explicitando suas críticas aos excessos do marxismo ortodoxo predominante na época. Apesar de se caracterizar como uma escola de pensamento, não era homogêneo teoricamente:

Esses pensadores constituíram a chamada "Escola de Frankfurt", pelo
fato de se estabelecerem enquanto um grupo de pesquisadores nesta
cidade alemã, criando aí o Instituto de Pesquisa Social e um órgão de
divulgação de suas produções, a Revista de Pesquisa Social.
Destacam-se entre seus membros Max Horkheimer (1895-1973),
Diretor do Instituto de 1930 até 1967; Herbert Marcuse (1898-1979),
mais conhecido no Brasil nos anos 1970, por seus livros aqui
publicados; Theodor Adorno (1903-1969), que ingressou no Instituto
no final dos anos 1930 e dirigiu-o de 1967 a 1969; Walter Benjamin
(1892-1940), bolsista do Instituto nos anos 1933-1940 e, ainda, Jürgen
Habermas (1929), filósofo e sociólogo, aposentado, mas atuante
intelectualmente. Desde 2001, o Diretor do Instituto de Pesquisa
Social é Axel Honneth (1949), filósofo e sociólogo (PUCCI, p. 02,
2013).

Para pensarmos a confluência do pensamento crítico e da Filosofia da Educação centremos nossas observações no pensamento adorniano e, mais especificamente, nos conceitos de Formação, Bildung (conferir Teoria da Semiformação, Adorno), e Semiformação ou Semicultura e Pseudoformação, Halbbildung (conferir Dialética do Esclarecimento, Adorno e Horkheimer).

Adorno adota ainda os conceitos de Esclarecimento e de Emancipação, ligados ao de Formação, de um modo análogo à concepção de Kant. Para os dois filósofos a Emancipação não é somente o desenvolvimento intelectual do pensamento, a superação da ignorância no processo histórico, mas também a capacidade dos homens de se libertar da dominação e opressão geradas por eles próprios. No texto Educação e Emancipação, Adorno cita Kant, quando em Resposta à pergunta: o que é esclarecimento? o filósofo

\begin{tabular}{|l|l|l|l|l|}
\hline Q Rovista Dialectus & Ano 2 & n.5 & Agosto - Dezembro 2014 & p. 125 - 139 \\
\hline
\end{tabular}


[...] define a menoridade ou tutela e, deste modo, também a emancipação, afirmando que este estado de menoridade é auto inculpável quando sua causa não é a falta de entendimento, mas a falta de decisão e de coragem de servir-se do entendimento sem a orientação de outrem (ADORNO, 1995, p.169).

Apesar da Teoria Crítica não ter uma tradição reflexiva voltada para a Educação, é possível encontrarmos no pensamento de Adorno uma produção significativa sobre o tema, como, por exemplo, os textos Tabus acerca da Educação, Educação após Auschwitz, Educação e Emancipação e Educação - Para quê? nos quais Adorno se dedicou a entender os processos de Formação do homem na sociedade buscando entender a lógica da burguesia industrial para defender mudanças na estrutura social, o que o levou a pisar no terreno da educação.

$\mathrm{O}$ pensamento adorniano relativo à Educação pressupõe críticas à indústria cultural, considerada como a principal responsável por diminuir a capacidade humana de agir com autonomia. Para ele, a sociedade capitalista aliena o homem das suas condições de vida e a crise da Educação é a mesma crise da formação cultural da sociedade capitalista como um todo. Dessa forma, a escola se transformou em um poderoso instrumento a serviço da indústria cultural, que trata o ensino como uma mera mercadoria pedagógica, quando deveria promover o domínio pleno do conhecimento e a capacidade de reflexão.

Daí a reflexão adorniana de uma educação crítica, emancipatória, que contribua não somente para o esclarecimento das contradições sociais e para a necessidade de sua superação, mas também que possa proporcionar a formação do homem, orientando-o para ações e estratégias emancipatórias. A educação, assim, seria um processo de libertação do homem, na luta contra a barbárie e como mediação para a emancipação humana, e fruto do pensamento crítico-reflexivo.

Adorno destaca a educação tanto no sentido amplo - aparatos institucionais como a família, os meios de comunicação, a difusão efetiva da cultura - como no sentido restrito - educação formal escolar da primeira infância à educação universitária. Reconhece que há uma vinculação necessária entre o esclarecimento e a emancipação, remetendo à possibilidade de autonomia do indivíduo e de transformação social, pois emancipação significa conscientização, racionalidade e, assim, a educação, no sentido

\begin{tabular}{|l|l|l|l|l|}
\hline Q Ronita Dialectus & Ano 2 & n.5 & Agosto - Dezembro 2014 & p. 125 - 139 \\
\hline
\end{tabular}


emancipatório, tem o importante papel de perceber a barbárie e revelar as suas raízes, examinando as condições para interferir em seu rumo.

Por conseguinte, para Adorno, o processo educacional tem um papel fundamental para a emancipação do homem, pois este é sujeito histórico, capaz de sair da sua menoridade e, assim, a educação pelo esclarecimento tanto pode contribuir contra a barbárie como para o advento da emancipação humana. A educação crítica prepara para o exercício do pensar e, portanto, para o esclarecimento. Daí vem seu potencial emancipatório. Adorno acredita neste potencial emancipatório da educação. Em seu texto Educação após Auschwitz, o filósofo afirma: "a educação tem sentido unicamente como educação dirigida e uma autorreflexão crítica".

A educação como esclarecimento envolve todo o processo formativo do homem, começando desde a infância, passando pela juventude, até a fase adulta, buscando as causas da barbárie para extingui-la e estabelecendo condições de autonomia do pensamento, da consciência e da liberdade do indivíduo. Portanto, deve ser realizada, principalmente, nas escolas e universidades, mas pode ser também através dos pais, de organizações, dos meios de comunicação e de outras instituições formativas (Adorno, 1995).

Tal como Kant, Adorno reconhece os limites do seu próprio tempo e vê que as instituições escolares constituem quase o protótipo da própria alienação social e, por isso, impedem o desenvolvimento individual dos homens. Por isso, é impositivo o esclarecimento dos professores, dos pais e dos alunos, "com quem os professores deveriam conversar sobre as questões cheias de tabus" (Adorno, 1995, p. 114). Além disso, seria preciso contrapor-se à ideologia da escola contrária a uma formação efetiva; explicar que a escola não constitui um fim em si mesma; proporcionar a liberdade intelectual e a formação do espírito e, por fim, melhorar a qualidade da formação dos professores, pois, segundo Adorno, a solução para grande parte dos problemas da educação escolar estaria também em uma "mudança no comportamento dos professores" (Ibid., p. 113).

Assim, os mais esclarecidos, os intelectuais, podem contribuir para uma prática pedagógica emancipatória, tendo, por isso, grande importância na função da desbarbarização e do esclarecimento, não somente através da educação escolar e universitária, mas também em outras atividades formativas como organizações grupais.

\begin{tabular}{|l|l|l|l|l|}
\hline Q Ronista Dialectus & Ano 2 & n.5 & Agosto - Dezembro 2014 & p. 125 - 139 \\
\hline
\end{tabular}


No entanto, Adorno afirma que "a ideia de emancipação, como parece inevitável com conceitos deste tipo, é ela própria ainda demasiado abstrata" (Ibid., p. 143), pois a ideologia e a organização do mundo em que vivemos ainda frustra toda tentativa de promover uma efetiva educação para o esclarecimento da consciência.

Daí termos somente a promoção da Semiformação (Halbbildung), como não autêntica realização da Formação (Bildung), como constituição frágil e débil da proposta de autonomia do sujeito livre, em virtude das deficiências formativas da indústria cultural e do consumismo exacerbado do capitalismo burguês.

Haveria, portanto, uma contraposição entre Formação e Semiformação, não sendo esta última um meio caminho para aquela, mas sim tanto um desvirtuamento quanto um obstáculo para a realização da Bildung. Não se realizando a educação como esclarecimento e nem, consequentemente, a conscientização dos indivíduos como alicerce para a saída da sua menoridade e nem tão pouco a superação da sociedade capitalista.

\section{4- Filosofia da Diferença e Filosofia da Educação}

O pensamento pós-moderno é uma reação à "monotonia" do mundo moderno caracterizado pelo positivismo, tecnocentrismo, racionalismo, crença no progresso linear e nas verdades absolutas, infalibilidade do planejamento racional e padronização do conhecimento e da produção. O pensamento pós-moderno, ao contrário, acredita na força libertadora da heterogeneidade, da diferença, da fragmentação, da indeterminação, descrê nos discursos universais e 'totalizantes', enfatiza a descontinuidade e o conceito de Diferença na história (MARINHO, 2009).

A Filosofia pós-moderna também proclama a morte das metanarrativas (Lyotard) que sustentavam uma pretensa história universal. No lugar de uma razão manipuladora e do fetiche da totalidade, típicas da Modernidade, fala-se agora de pluralismos, de heterogeneidade de jogos lingüísticos. A ciência e a filosofia devem renunciar às suas pretensiosas explicações metafísicas e se reconhecerem como narrativas comuns entre tantas outras. Contudo, efetivamente o que distingue o pensamento pós-moderno é a noção de différence [diferença], que vários pensadores

\begin{tabular}{|l|l|l|l|l|}
\hline Q Rovista Dialectus & Ano 2 & n.5 & Agosto - Dezembro 2014 & p. 125 - 139 \\
\hline
\end{tabular}


(Deleuze, Lyotard, Vattimo, Derrida, dentre outros) utilizam, desenvolvem e aplicam de formas variadas e que tem sua origem em Nietzsche, em Saussure e em Heidegger.

Deleuze, o filósofo que norteará a presente reflexão, desenvolve todo um pensamento pautado na diferença. Assim, em 1962, no livro Nietzsche e a filosofia, “interpreta a filosofia de Nietzsche como uma crítica à dialética hegeliana, uma crítica que está baseada precisamente no conceito de "diferença"” (Peters, 2000, p. 43). Esse livro, segundo Peters, foi fundamental para a emergência de uma filosofia da diferença.

A filosofia da diferença se distancia da visão clássica da filosofia da representação ao fazer uma crítica radical à representação, seja em sua vertente aristotélica, seja em sua vertente hegeliana e propondo, fortemente, a inversão do platonismo, com o objetivo expresso de rejeitar a identidade como parâmetro filosófico e resgatar a importância e a centralidade da diferença como estatuto ontológico.

Assim, se a filosofia da diferença propõe uma filosofia da imanência, é certo que uma filosofia da educação pensada a partir da filosofia da diferença não será como a filosofia da educação pautada nos moldes clássicos da filosofia da representação. A abordagem clássica da filosofia da educação propõe que se parta dos clássicos da filosofia que, de alguma forma, falaram sobre educação ou que seja uma proposta de pressupostos filosóficos que norteariam a atividade pedagógica, e no caso da filosofia iluminista prevalece a ideia da Formação (Bildung), da qual a Teoria Crítica é herdeira.

Dessa forma, diante da inexistência de um centro, de um fundamento, deixa de fazer sentido uma Filosofia da Educação que fundamente metafisicamente o discurso pedagógico: “A filosofia da educação pode ser muito importante, mas não no sentido de dar a si mesma e às várias teorias pedagógicas um critério de verdade excepcional, que sustente a ela mesma e sustente qualquer ciência ou teoria a respeito de educação" (Ghiraldelli, 2000, p. 19).

A confluência da filosofia da diferença e da filosofia da educação abriu novos caminhos para se pensar, por exemplo, o currículo não mais como algo estanque, bem como vislumbrou os limites da teoria crítica mediante os novos acontecimentos contemporâneos. A instabilidade, a incerteza e a desordem, trazidas pelo fim dos fundamentos, propiciaram outros tipos de pensamentos e de ações políticas que não têm mais a ideia de referencial e de fundamento presentes na teoria crítica.

\begin{tabular}{|l|l|l|l|l|}
\hline Q Rovista Dialectus & Ano 2 & n.5 & Agosto - Dezembro 2014 & p. 125 - 139 \\
\hline
\end{tabular}


No campo da educação, orientado tradicionalmente pela identidade, diz Tomaz Tadeu, a Filosofia da Diferença, principalmente a deleuzeana, pode servir de grande inspiração no questionamento do sujeito moderno, da verdade pretendida pelos currículos, dos valores disfarçados nos programas escolares e do poder subsumido na disciplina escolar. Sendo assim, não se conhece para libertar a humanidade e promover o progresso contínuo do mundo e da civilização, ou para descobrir a verdade e sair da caverna, mas conhecer é interpretar e "interpretar é dar sentido, impor uma ordem, uma forma, uma direção, é dar um sinal à massa informe e caótica das coisas do mundo. Interpretar não é revelar, descobrir, identificar, mas criar, inventar, produzir" (Silva, 2002 a, p. 10).

Dessa forma, um currículo que seguisse a linha da filosofia da diferença, seria perspectivista, sem um sujeito centralizador e centralizado, sem a crença em uma verdade única a ser alcançada e ensinada por um professor-profeta, mas seria um currículo aberto, sem imposição de valores e de poderes, sem a imposição da disciplina. Deveria, por fim, visar à singularidade dos sujeitos e não sua subjetivação massificadora.

Daniel Lins (2005), por sua vez, reconhece a existência de uma pedagogia que não pensa e que é, por isso, lugar da exclusão. Daí propor uma escola diferente, na qual seja trabalhado o pensamento conjuntamente com os afectos, pois ambos não se separam. Essa separação, contudo, é realizada por uma pedagogia que se apoia no discurso da representação. Inclusive, para Lins, somente uma pedagogia que veja conjuntamente pensamento e afecto pode possibilitar a emergência da diferença. Podese chamar essa pedagogia de "pedagogia do acontecimento", que se contrapõe a uma pedagogia da representação. A pedagogia do acontecimento funciona por linhas de fuga que possibilitam a invenção, a descoberta, a desterritorialização.

Lins, deleuzeanamente, cria o conceito de Mangue's School para nominar a escola da pedagogia do acontecimento. A metáfora é significativamente deleuzeana por tomar o mangue como referência por ele ser rizomático. Assim, há uma contraposição à árvore do conhecimento, ideia tradicional da filosofia da representação. Para a pedagogia e a escola rizomáticas, a criança é um devir afirmativo que se basta a si mesmo; é um acontecimento; e o saber que ela aprende deve ser/ter sabor. Ou seja, o aprender deve ser prazeroso, sem os castigos da disciplina e da ideia da culpa. Por isso,

\begin{tabular}{|l|l|l|l|l|}
\hline Govista Dialectus & Ano 2 & n.5 & Agosto - Dezembro 2014 & p. 125 - 139 \\
\hline
\end{tabular}


a ética que acompanha a pedagogia e a escola rizomáticas é a ética dos afectos. É uma pedagogia molecular que se rege pelos desejos e pelo encontro com o Outro que, por sua vez, não se reduz a uma alteridade humana, mas ampliada até o não-humano. Assim, uma pedagogia rizomática que se sustenta em uma ética dos afectos deve ser uma pedagogia da invenção e do experimento, pois tudo é devir e acontecimento.

Walter Kohan (2010), a partir de uma confessa inspiração deleuzeana, também questiona o ensino, inclusive o da filosofia, como transmissão de saber, tal qual defendido e exercido pela tradição representacionista. A temática aprender/ensinar, baseada em Deleuze (1988) e também em Rancière (2004), afirma que não há nada a aprender e nada a ensinar como doação. Ninguém ensina a alguém, ninguém aprende de alguém. Nesse sentido, não há transmissão de saber, de conhecimento. Portanto, a aprendizagem se dá com alguém, e o que é aprendido é sempre reinventado.

Nessa mesma perspectiva, é problemático, também para Kohan, a ideia de conhecimento como emancipação, pois ninguém emancipa ninguém. A própria pessoa se emancipa. E, assim, a ideia de uma educação emancipadora, que advém do conhecimento repassado pelo professor, aprendido pelo aluno e responsável pela elevação de sua racionalidade é totalmente arbitrária. A educação não emancipa, pois a emancipação é um ato individual. A educação que visa à emancipação do outro, na verdade, embrutece o outro. Assim, então, o que a educação pode fazer é possibilitar que o outro se emancipe.

É também baseado em Deleuze que Sílvio Gallo (2003) valoriza o que ele chama de "educação menor" como aposta nas minorias e na possibilidade de emergência das diferenças, desfocando a importância exacerbada dada às grandes políticas.

Em um campo educacional fortemente marcado pelo pensamento tradicional da representação, toda teoria e práticas educacionais também estão na esfera da representação, da mesma forma que nos incita a ter uma visão representacional do mundo. O pensamento de Deleuze, então, se mostra como uma alternativa a esse pensamento dogmático, pois possibilita pensar a partir do múltiplo e não mais da identidade.

Nessa perspectiva, o pensamento deve ser invenção e não recognição. E é a partir da diferença, da multiplicidade que se deve pensar a educação. Inclusive a própria

\begin{tabular}{|l|l|l|l|l|}
\hline Q Ronita Dialectus & Ano 2 & n.5 & Agosto - Dezembro 2014 & p. 125 - 139 \\
\hline
\end{tabular}


Filosofia da Educação e o Ensino de Filosofia devem ter novos olhos para o universo educacional. Ou seja, devem conduzir seus agenciamentos a partir da diferença.

Em primeiro lugar, isso significa que a Filosofia da Educação não pode ser a disciplina empobrecedora e pobre que tem sido até agora, quando se propõe a ser simplesmente reflexão sobre a educação e fundamento da educação. Uma filosofia da educação, baseada na Filosofia da Diferença, há de ser criação de conceitos. Ou seja, não pode ser somente um agente passivo diante da realidade e ficar em um exercício de reconhecimento e recognição dessa realidade, muitas vezes conduzindo interesses de poderes conservadores e reacionários.

Em segundo lugar, nessa Filosofia da Educação há que se fortalecer a educação menor mediante a educação maior. Há que se proceder a uma desterritorialização dos componentes da educação maior para a educação menor. A oficialidade, o planejamento, as políticas públicas, máquina de controle e de subjetivação etc., que caracterizam a educação maior, devem ser combatido pela educação menor, em um movimento de uma máquina de guerra, de resistência, de produção de singularidades, de possibilidade do surgimento do inusitado na aprendizagem.

Essa educação menor deve, por sua vez, se ramificar e buscar o coletivo, mas não no sentido tradicional da macro política, pois, do contrário, haveria uma reterrritorialização. Trata-se de ser uma coletivização rizomática, sem preocupação com a totalidade e o universal. Interferir rizomaticamente, ou seja, no meio, no entre, nas conexões. É aí que entra a figura do professor-militante, que atua nas brechas, nos intervalos das pequenas coisas cotidianas, pois não há mais espaço para a figura do professor-profeta, aquele que traz grandes salvações para grandes problemas e para grandes multidões e que visa a emancipação.

\section{5- Conclusão}

Filiamo-nos aqui a esse grupo de pensadores marxistas que defendem que as questões trazidas pelo pensamento pós-moderno e pela Filosofia da Diferença só poderão de fato ser legitimamente avaliadas se compreendidas na perspectiva históricosocial e à luz das grandes contribuições trazidas pela Modernidade. Entretanto, é necessário levar em consideração os subsídios extremamente positivos da reflexão pós-

\begin{tabular}{|l|l|l|l|l|}
\hline Gonista Dialectus & Ano 2 & n.5 & Agosto - Dezembro 2014 & p. 125 - 139 \\
\hline
\end{tabular}


moderna, por possibilitarem uma ampliação de reflexões a partir da quebra do universo monolítico da Modernidade.

Fica descartado aí, então, duas das grandes bandeiras do projeto emancipatório iluminista presente na Teoria Crítica: a educação como emancipação e o professor como responsável pela transmissão do saber que emanciparia. E, nesse âmbito, a crença na grande política também vai de roldão. Da mesma forma que as grandes narrativas foram desacreditadas pela pós-modernidade, as macro políticas que as acompanham também foram postas em xeque. A importância é dada agora às micro políticas.

Talvez um dos maiores méritos da inspiração deleuzeana na Filosofia no Brasil, incluindo a Filosofia da Educação, foi precisamente essa liberdade de filosofar, que é própria à Filosofia e, portanto, a possibilidade de um distanciamento ou revisão dos moldes canônicos do método estruturalista trazido pelos franceses na fundação da USP. Não que se tenha de abrir mão dos textos clássicos, mas, como Deleuze e Guattari alertam, são necessários cuidados para não nos contentarmos em simplesmente agitarmos velhos conceitos estereotipados que se assemelham a esqueletos que intimidam a criação de novos conceitos. Afinal, se fazemos filosofia (ou pretendemos) temos que fazer o que os filósofos faziam, ou seja, filosofia como criação de conceitos, pois "eles criavam seus conceitos e não se contentavam em limpar, em raspar os ossos, como o crítico ou o historiador de nossa época" (Deleuze e Guattari, 1992, p. 109).

Outro aspecto importante dessa inspiração deleuzeana na Filosofia da Educação é a ideia que Deleuze retoma de Kierkegaard e de Nietzsche das figuras de "pensador privado: pensador-cometa: portador da repetição" e "professor público: doutor da lei: portador da mediação, da generalidade dos conceitos, da moralização" (Deleuze, 1988) e que remete às figuras do professor-profeta e professor-militante. Assim, nossa tradição de professores de filosofia tem seguido os rastros do professor-privado e do professorprofeta e, mais grave ainda, em nossa função de formadores de professores de filosofia temos repassado essa tradição, nos reproduzindo em série. Fica, então, a possibilidade do espelho nos mostrar que podemos procurar os caminhos do pensador-privado e do professor-militante.

Uma última observação é sobre a importância da filosofia da diferença deleuzeana considerar a imanência tão importante e revolucionária ao ponto de afirmar que ela é "a pedra de toque incandescente de toda a filosofia" (Deleuze e Guattari, 1992,

\begin{tabular}{|l|l|l|l|l|}
\hline Q Rovista Dialectus & Ano 2 & n.5 & Agosto - Dezembro 2014 & p. 125 - 139 \\
\hline
\end{tabular}


p. 63). Essa importância dada à imanência repercute de forma intrigante em um país marcado filosoficamente pela metafísica e por todos os desdobramentos filosóficos da representação, inclusive uma certa feição do marxismo ortodoxo.

\section{REFERÊNCIAS}

ADORNO, T.W. Educação e Emancipação, São Paulo: Paz e Terra, 1995.

DELEUZE, Gilles. Diferença e repetição. Tradução Luiz Orlandi, Roberto Machado. Rio de Janeiro: Graal, 1988.

DELEUZE, Gilles, GUATTARI, Félix. O que é a filosofia? Tradução de Bento Prado Jr. E Alberto Alonso Muñoz. Rio de Janeiro: Ed. 34, 1992. (Coleção TRANS).

GALLO, Silvio. Deleuze \& a educação. Belo Horizonte: Autêntica, 2003.

GHIRALDELLI JÚNIOR, Paulo. (Org.). Estilos em educação. Rio de Janeiro: DP\&A, 2000.

KANT, Immanuel. Resposta à pergunta: o que é "esclarecimento"? (Aufklärung). In: Textos Seletos / Introdução de Emmanuel Carneiro Leão. 3. ed. Petrópolis: Vozes, 2005.

KOHAN, Walter O. O ensino de filosofia e a questão da emancipação. In: Filosofia: ensino médio/ Coordenação, Gabriele Cornelli, Marcelo Carvalho e Márcio Danelon. Brasília: Ministério da Educação, Secretaria e Educação Básica, 2010. 212 p.: il. (Coleção Explorando o Ensino; v. 14). Disponível em portal.mec.gov.br Acessado em agosto de 2011.

LINS, Daniel. Mangue's school ou por uma pedagogia rizomática. In: Revista Educação e Sociedade, Campinas, vol. 26, n. 93, p. 1229-1256, Set./Dez. 2005. Disponível em http://www.cedes.unicamp.br

MARINHO, Cristiane M. A Filosofia da Diferença de Gilles Deleuze na Filosofia da Educação no $\quad$ Brasil. $2012 . \quad$ Disponível em: http://www.bibliotecadigital.unicamp.br/document/?code $=000851942$

MARINHO, Cristiane M. Pensamento pós-moderno e educação na crise estrutural do capital. Fortaleza, EDUECE, 2009. 355 p.

MARINHO, C. M.; FURTADO, E.; MOURA, E. M.; COELHO, M. H. M.; Filosofia da educação: pressupostos e perspectivas. In: Filosofia da educação. Licenciatura em Pedagogia. Fortaleza: RDS, 2009.

PETERS, Michael. Pós-estruturalismo e filosofia da diferença. Tradução de Tomaz Tadeu da Silva. Belo Horizonte: Autêntica, 2000. (Coleção Estudos Culturais, 6).

PUCCI, Bruno. GT Filosofia da Educação - ano 20: contribuições da teoria crítica da sociedade. 2013. Disponível em:

http://portal_anped.verkn.com.br/grupos-de-trabalho-comite-cientifico/grupos-detrabalho/grupos-de-trabalho/gt17

RANCIÉRE, Jacques. $O$ mestre ignorante - cinco lições sobre a emancipação intelectual. $2^{\mathrm{a}}$ ed. Belo Horizonte: Autêntica, 2004.

TOMAZETTI, Elisete M. Filosofia da educação: um estudo sobre a história da disciplina no Brasil. Ijuí: Ed. Unijuí, 2003. Coleção fronteiras da educação.

MARINHO, Cristiane. Filosofia e Educação no Brasil. 1 ${ }^{a}$ Edição. São Paulo: Edições Loyola, 2014. 254 p.

\begin{tabular}{|l|l|l|l|l|}
\hline Q Ronista Dialectus & Ano 2 & n.5 & Agosto - Dezembro 2014 & p. 125 - 139 \\
\hline
\end{tabular}

